This is an electronic reprint of the original article. This reprint may differ from the original in pagination and typographic detail.

Author(s): Kokko, Katja

Title: Adult Development

Year: $\quad 2018$

Version:

Please cite the original version:

Kokko, K. (2018). Adult Development. In M. H. Bornstein (Ed.), The SAGE

Encyclopedia of Lifespan Human Development (pp. 60-61). Sage Publications.

https://doi.org/10.4135/9781506307633.n28

All material supplied via JYX is protected by copyright and other intellectual property rights, and duplication or sale of all or part of any of the repository collections is not permitted, except that material may be duplicated by you for your research use or educational purposes in electronic or print form. You must obtain permission for any other use. Electronic or print copies may not be offered, whether for sale or otherwise to anyone who is not an authorised user. 


\section{ADULT DEVELOPMENT}

\section{Adulthood}

This entry focuses on two concepts: adulthood and psychological development. Adulthood is an extensive period of life, starting around age 20. Adult development is linked to childhood and adolescence development but is not determined by them. Even if unfavorable early experiences, such as a child's aggressive behavior, are generally associated with adult difficulties, a warm family environment may prevent this type of development. Adulthood comprises several phases, defined as early (20-34 years), middle (35-60 years), and later adulthood (60 years and older), each with its typical developmental tasks and psychosocial crises. The specific age boundaries of the phases vary somewhat across theoreticians. Adulthood has traditionally been defined as arriving when certain developmental tasks have been established; these tasks concern intimate relationships, childbearing, work, and lifestyle. Early adulthood is typically characterized by engaging in these tasks, middle adulthood by their maintenance, and later adulthood by coping with changes in life domains.

In the $21^{\text {st }}$ century, more individual variation in the completion, timing, and sequence of the developmental tasks of adulthood has been observed and tolerated than ever before. The lengthened period of identity and role exploration between early and middle adulthood, typical in Western countries, is known as emergent adulthood or delayed transition to adulthood (extending up to age 30). A successful resolution of psychosocial crises in adulthood, as described in Erik H. Erikson's classic theoretical work, results in a feeling of intimacy in early adulthood, generativity in middle adulthood, and integrity in later adulthood. Yet another way to conceptualize adulthood is to rely on self-perceptions that one is a responsible and independent adult. 


\section{General Remarks on Adult Psychological Development}

Adult development can be analyzed by drawing on the psychological theories of human development. In the lifespan theory, development occurs throughout life and no single phase predominates. Further, development is seen as plastic, as it includes both gains and losses which individuals handle using various strategies and coping mechanisms. The life course theory in turn postulates that an individual's development is both interlinked with the lives of other persons, such as the links between parents and children or between spouses, and regulated by the individual's own choices. These choices are made within certain boundaries, such as age, culture, and historical time.

In the psychological theories of human development, middle adulthood (around ages 35-60) is considered a particularly noteworthy life phase. Mid-adulthood is at the intersection of early development and later adulthood, and thus plays a role in how an individual negotiates the

increasing number of losses experienced in later life. Further, middle-aged adults often have high profiles in work and the community and have several responsibilities of care, such as those related their own children and grand-children as well as aging parents.

Psychological development can mean different things, such as the emergence of a qualitatively new behavior or characteristic, or a quantitative increase or decrease in these. Qualitative developmental changes, such as the emergence of a new skill, are more visible in child than adult development. Consequently, adult development is often analyzed as an absolute change in the amount of the characteristic of interest. Information on age differences in a particular characteristic can be obtained by comparing groups of individuals at different ages, as is done in cross-sectional studies. However, any observed difference may be explained by the shared historical context of same-aged individuals - rather than by age or development per se. 
The most reliable information on developmental changes can be obtained by following the development of the same individuals across time, as is done in longitudinal studies.

\section{Specific Features of Adult Psychological Development}

Certain average developmental trends have been observed in the main areas of adult psychological functioning, such as personality, mental well-being, and cognitive abilities. Personality can be conceptualized as consisting of different layers. The first layer comprises rather stable dispositional characteristics (e.g., temperament, personality traits), the second motivational characteristics (e.g., goals, strivings), and the third an individual's self-narrative of his or her life history.

With respect to the personality traits present in the first layer, people tend to become more emotionally stable, conscientious, and agreeable with age, particularly up to late middle adulthood. Developmental changes of this kind are often described as following a maturity principle. They are further assumed to associate with positive functioning in adult social roles, such as social relationships and work. It has, however, been questioned whether the observed changes do not rather reflect adjustment to these social roles than personality maturation, which would be implied if openness to new experiences, representing intellectual curiosity, increased across adulthood. A concern for the next generation and its guidance, called generativity, is an example of a characteristic from the second personality layer that becomes more important in mid-adulthood than in the earlier or later phases of adulthood. Further, the attempt to make a coherent story of one's life, from the third layer of personality, becomes an increasingly prominent aspect of personality throughout adulthood.

Mental well-being includes dimensions related to maximizing one's happiness and to actualizing one's potential. Happiness is indicated by a general satisfaction with life and positive 
emotions, whereas self-actualization is implied by personal growth and finding a meaning in life. On average, both life satisfaction and positive emotions seem to increase with age in adulthood. Furthermore, finding a meaning in life seems to become increasingly important, particularly in later adulthood. There is no unambiguous evidence of developmental changes in personal growth across the adult years. The generally positive development of mental well-being contradicts the popular conception of a mid-life crisis. Despite this positive well-being trend, depression is a common feeling in very old adulthood. It is often intertwined with loneliness and cognitive impairments, the risks for which increase with the years.

Generally, cognitive abilities resist impairment with aging for quite a long time: K. Warner Schaie has shown, based on longitudinal studies, that inductive reasoning, spatial orientation, numeric and verbal ability, and verbal memory remain at a stable level until around age 60 , after which they modestly decline until age 80 , after which they decrease more sharply. The only cognitive ability showing a linear decrease already after age 25 is perceptual speed.

However, single cognitive abilities are only one part of cognitive functioning. Wisdom is an example of a type of cognitive functioning that requires extensive co-operation between different cognitive abilities, as well as with motivational and affective characteristics. Wisdom represents an exceptionally high level of human knowledge and expertise that can be used for the well-being of others as well as the person him- or herself. Wisdom is an outcome of experiences accumulated during the developmental years and, consequently, it cannot peak until adulthood. Only a small proportion of adults accumulate a high level of wisdom even in late life.

It is important to note that the average developmental trends in adult psychological development described here do not illustrate development at the individual level, where there is a lot of heterogeneity, due, for example, to gender, childhood experiences, health, education, 
work- and family-roles, and life events. Further, it should be noted that in very old age actively seeking to maintain one's functioning - for example, resisting the general trend towards declining cognitive functioning - can be seen as a positive development.

Katja Kokko

See also: Cognitive Development, Developmental Plasticity, Emerging Adulthood, MiddleAge/Midlife, Old Age, Personality, Transition to Adulthood, Well-Being

\section{Further Readings}

Arnett, J. J. (2000). Emerging adulthood: A theory of development from the late teens through the twenties. American Psychologist, 55, 469-480.

Baltes, P. B. (1997). On the incomplete architecture of human ontogeny: Selection, optimization, and compensation as foundation of developmental theory. American Psychologist, 52, 366-380.

Elder, G. H. (1998). The life course as developmental theory. Child Development, 69, $1-12$.

Erikson, E. H. (1963). Childhood and society. New York: Norton.

Havighurst, R. J. (1982). Developmental tasks and education. New York: Longman. (Original work published 1948)

Lachman, M. E., Teshale, S., \& Agrigoroaei, S. (2015). Midlife as a pivotal period in the life course: Balancing growth and decline at the crossroads of youth and old age. International Journal of Behavioral Development, 39, 20-31.

McAdams, D. P., \& Olson, B. D. (2010). Personality development: Continuity and change over the life course. Annual Review of Psychology, 61, 517-542. 
Ryff, C. D. (1989). Happiness is everything, or is it? Explorations on the meaning of psychological well-being. Journal of Personality and Social Psychology, 57, 1069-1081.

Schaie, K. W. (1994). The course of adult intellectual development. American

Psychologist, 49, 304-313.

Staudinger, U. M., \& Kunzmann, U. (2005). Positive adult personality development: Adjustment and/or growth? European Psychologist, 10, 320-329. 